\title{
KEWENANGAN OTONOMI DAERAH: SISTEM PERTANAHAN DAERAH ISTIMEWA YOGYAKARTA
}

\author{
Jaenudin Umar \\ Universitas Swadaya Gunung Jati Cirebon \\ jaenudinumar@gmail.com
}

Received : 08-01-2021

Revised : 17-02-2021

Accepted : 22-02-2021

\begin{abstract}
This study aims to examine more deeply the land polemic in DI Yogyakarta. In addition, the land policy authority applied in DI Yogyakarta is in accordance with Law Number 32 of 2004, namely regional autonomy which aims to provide welfare for the community. The description of important points in this paper is the land history of the Special Region of Yogyakarta, the implementation of the land system in the Special Region of Yogyakarta, and the management and utilization of the land of the Sultanate and the Duchy. These three things are processed using normative legal methods with a statutory approach as primary legal materials. The analysis was conducted qualitatively with a descriptive analysis writing system. The results of the study can be concluded that there is a dualism of land law in DI Yogyakarta, namely national law (UUPA) and customary law (Rijkshblaad). Mediating the polemic, then Law no. 13 of 2012 concerning special autonomy for DI Yogyakarta functions to regulate its own household affairs, including the land system. The land system in DI Yogyakarta is different from other regions in order to preserve the historical origins of DI Yogyakarta's land history. Regional autonomy has a purpose for the welfare of society. Management and utilization of the Sultanate and Kadipaten lands for cultural, social and public interests by obtaining permits from both the Sultanate and the Kadipaten.
\end{abstract}

Key words: bureaucratic pathology; public service.

\begin{abstract}
Abstrak
Penelitian ini bertujuan untuk mengkaji lebih dalam mengenai polemik pertanahan di D.I Yogyakarta. Selain itu, kewenangan kebijakan pertanahan yang diterapkan di D.I Yogyakarta apakah sesuai dengan Undang-Undang Nomor 32 Tahun 2004 yaitu otonomi daerah bertujuan untuk memberikan kesejahteraan bagi masyarakat. Uraian poin penting dalam penulisan ini yaitu sejarah pertanahan Daerah Istimewa Yogyakarta, pelaksanaan sistem pertanahan di Daerah Istimewa Yogyakarta, serta pengelolaan dan pemanfaatan tanah Kasultanan dan Kadipaten. Ketiga hal tersebut diolah menggunakan metode hukum normatif dengan pendekatan perundang-undangan sebagai bahan
\end{abstract}


hukum primer. Analisis dilakukan secara kualitatif dengan sistem penulisan bersifat deskriptif analisis. Hasil penelitian dapat disimpulkan bahwa adanya dualisme hukum pertanahan D.I Yogyakarta yaitu hukum nasional (UUPA) dan hukum adat (Rijkshblaad). Penengah atas polemik tersebut, maka muncul Undang-Undang No. 13 Tahun 2012 tentang otonomi khusus bagi D.I Yogyakarta berfungsi untuk mengatur urusan rumah tangganya sendiri, termasuk sistem pertanahan. Sistem pertanahan yang ada di D.I Yogyakarta berbeda dengan daerah lain guna menjaga asal usul sejarah pertanahan D.I Yogyakarta. Otonomi daerah mempunyai tujuan untuk mensejahterakan masyarakat. Pengelolaan dan pemanfaatan tanah Kasultanan dan Kadipaten untuk kepentingan kebudayaan, kepentingan sosial serta kepentingan publik dengan didapatkannya perizinan baik dari Kasultanan maupun Kadipaten.

Kata kunci: patologi birokrasi; pelayanan publik.

\section{Corresponden Author : Jaenudin Umar}

Email : jaenudinumar@gmail.com

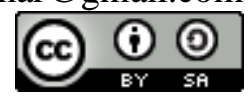

\section{PENDAHULUAN}

Desentralisasi sebagai suatu asas yang hampir dianut setiap negara dalam penyelenggara pemerintahan. Nilai desentralisasi merupakan perwujudan dari otonomi daerah yaitu pembentukan daerah otonom dan penyerahan kewenangan untuk menyelenggarakan urusan-urusan pemerintahan yang telah diserahkan atau diakui sebagai domain rumah tangga daerah otonom tersebut. Hubungan antara pemerintah daerah dan pemerintah pusat tergantung apakah bentuk negara tersebut negara kesatuan, negara federal atau negara serikat (Nadir, 2013).

Indonesia adalah negara kesatuan dimana pemerintah pusat memiliki kekuasaan untuk mengatur dan memimpin seluruh daerah. Tetapi dengan kebijakan otonomi daerah, pemerintah daerah memiliki kebebasan wewenang untuk mengatur daerahnya sendiri. Hubungan antara pemerintah daerah dan masyarakat dianggap lebih dekat sehingga diharapkan dapat merealisasikan aspirasi dan keinginan masyarakat karena lebih mengetahui kondisi daerah tersebut (Alivia, 2019). Hal ini sesuai dengan amanat UndangUndang Nomor 32 Tahun 2004, yaitu otonom daerah memiliki wewenang dalam mengatur dan mengurus kepentingan masyarakat setempat dengan prakarsa sendiri menurut aspirasi masyarakat dan sesuai perundang-undangan. Hal ini diarahkan untuk menuju kesejahteraan masyarakat melalui peningkatan, pelayanan, pemberdayaan, dan peran serta masyarakat, serta peningkatan daya saing daerah (Baharudin, 2016).

Daerah Istimewa Yogyakarta menjadi salah satu pemerintahan daerah yang memiliki keistimewaan. Sejarah dari Yogyakarta sebagai suatu kerajaan yang memilki hukum adat yang tidak bisa disamakan dengan daerah lain. Seperti yang tercantum dalam UndangUndang No.13 Tahun 2012. Keistimewaan tersebut meliputi kewenangan dalam hal : a) tata cara pengisian jabatan, kedudukan, tugas dan wewenang Gubernur dan Wakil 
Gubernur, b) kelembagaan, c) kebudayaan, d) pertanahan dan e) tata ruang (Annafie \& Nurmandi, 2017).

Terjadi dualisme hukum nasional dan hukum adat dalam kewenangan pemerintahan daerah, D.I Yogyakarta dalam sistem pertahanan yang mengatur mengenai hak kepemilikan tanah keraton. Penelitian ini akan mengkaji lebih dalam mengenai polemik pertanahan dengan otonomi khusus di D.I Yogyakarta. Selain itu, kewenangan kebijakan tersebut apakah sesuai dengan Undang-Undang Nomor 32 Tahun 2004 yaitu otonomi daerah bertujuan untuk memberikan kesejahteraan bagi masyarakat.

\section{METODE PENELITIAN}

Metode penelitian dilakukan menggunakan hukum normatif dengan pendekatan perundang-undangan. Metode pendekatan yang didasarakan pada kepustakaan yang kemudian dikaitkan dengan bahan hukum primer yaitu Undang-Undang No. 32 Tahun 2004 mengenai otonomi daerah, Undang-Undang No. 13 Tahun 2012 tentang Otonomi Khusus Daerah Istimewa Yogyakarta, dan Perdais Daerah Istimewa Yogyakarta Nomor 1 Tahun 2017 mengenai Pengelolaan dan Pemanfaatan Tanah Kasultanan dan Kadipaten. Data yang didapatkan kemudian disusun secara sitematis dan dianalisis secara kualitatif. Sistem penulisan bersifat deskriptif kualitatif yaitu berupa uraian permasalahan dan solusi berdasarkan data yang telah didapatkan.

\section{HASIL DAN PEMBAHASAN}

\section{Sejarah Pertanahan Daerah Istimewa Yogyakarta}

Kesepakatan perjanjian Giyanti 13 Febuari 1755 awal mula sejarah kepemilikan tanah Kesultanan Yogyakarta. Raja memiliki dominan kepemilikan tanah dan rakyat mempunyai hak untuk menggarap tanah (magersari). Rakyat juga mempunyai kewajiban untuk meyerahkan hasil garapan tanah tersebut. Selain menyerahkan sebagian hasil tanamnya, rakyat juga diwajibkan bekerja di perusahaan-perusahaan pertanian (Putriyanti, 2014).

Terjadi perubahan sistem pertanahan di D.I Yogyakarta pada tahun 1918 yang diatur dalam Rijksblaad Kesultanan No. 16 Tahun 1918 dan Rijksblaad Pakualaman No. 18 tahun 1918. Raja melepaskan bagian hak tanah wilayahnya milik untuk pribumi anggota masyarakat desa dan penduduk desa. Berdasarkan kedua aturan tersebut juga muncul istilah swaparaja yaitu Sultanaat Ground dan Pakualaman Ground. Jika penduduk maupun pemerintahan desa ingin mengelola tanah milik keraton, maka harus mendapatkan ijin dari Sultanaat Ground. Hal ini juga berlaku untuk Pakualaman Ground (Lestarini, 2018).

Namun, aturan Rijksblaad menimbulkan problematika sistem pertanahan di D.I.Y yaitu tanah yang berstatus megarsari. Hal ini karena masyarakat sudah mengelola tanah megarsari secara turun temurun sebagai sumber mata pecaharian mereka. Walaupun, sebenarnya tanah tersebut milik Kesultanan dan Pakualaman.

Salah satu kasus yang membuktikan bahwa Daerah Istimewa Yogyakarta masih menerapkan aturan Rijksblaad adalah kasus di Kulonprogo tahun 2008. Tanah megarsari yang dikelola masyarakat untuk pertanian secara turun temurun akan dialihkan fungsi menjadi pabrik pengolahan biji besi. Masyarakat menolak atas kebijakan tersebut, akan tetapi masyarakat dalam keadaan lemah karena tanah tidak bersertifikat atas nama masyarakat. Oleh karena itu, tanah adalah milik Keraton dan Pakulaman menurut Rijksblaad. 


\section{Pelaksanaan Sistem Pertanahan Daerah Istimewa Yogyakarta}

Diturunkannya Undang-Undang No. 5 Tahun 1960 maka, telah dihapuskannya aturan urusan agraria sebagai kewenangan otonom. Akan tetapi, pada pasal 4 ayat (4) UU No. 3 Tahun 1950 dan Peraturan menteri Dalam Negeri No. 1 Tahun 1967 yang mengatur mengenai kewenangan agraria di Daerah Istimewa Yogyakarta. Menyebabkan masih berkembangnya ketentuan-ketentuan otonom agraria. Selain itu, UndangUndanng No. 13 Tahun 2012 tentang aturan keistimewaan DIY yang memiliki kewenangan otonom untuk mengatur rumah tangganya sendiri. Salah satu kewenangan tersebut adalah sistem pertanahan yang berbeda dengan daerah lain.

Dasar hukum yang mengatur pertanahan saat ini Di Daerah Istimewa Yogyakarta adalah UUPA pasal 33 ayat (3). Melalui perda D.I Yogyakarta No. 1984 Sultanaat Ground dan Pakualaman Ground yang sudah dihapuskan oleh HB IX, PA VIII, beserta DPRD (Rahmasari, 2016). Dualisme pelaksanaan hukum pertanahan Daerah Istimewa Yogyakarta antara aturan lama Rijksblaad yang sebenarnya telah dihapuskan dan hukum nasional UUPA di DIY. Sejarah yang kuat di DIY sebagai suatu daerah kerajaan tidak bisa serta merta melupakan pola kebiasaan kehidupan masyarakat yang sudah memiliki karakteristik tersendiri dalam pola pemerintahan di DIY. Oleh karena itu, kultur kepemimpinan Gubernur sekaligus Kesultanan dan kepatuhan masyarakat itu sendiri berbeda dengan daerah lain. Mengakibatkan aturan Rijksblaad masih berlaku di DIY dan UUPA sebagai hukum nasional tidak bisa diberlakukan secara menyeluruh sehingga menimbulkan ketidakpastian hukum (Jati, n.d.).

\section{Pengelolaan dan Pemanfaatan Tanah Kasultanan dan Tanah Kadipaten}

Undang-Undang Nomor 32 Tahun 2004, yaitu otonom daerah memiliki wewenang dalam mengatur dan mengurus kepentingan masyarakat setempat dengan melihat kondisi wilayah tersebut sesuai perundang-undangan. Hal ini diarahkan untuk menuju kesejahteraan masyarakat melalui peningkatan, pelayanan, pemberdayaan, dan peran serta masyarakat, serta peningkatan daya saing daerah. Tujuan Undang-Undang Nomor 32 Tahun 2004 dengan sistem pelaksanaan otonom pertanahan di D.I Yogyakarta adakah kesesuaian. Secara hukum adat, tanah yang ada di wilayah D.I Yogyakarta adalah hak Sultan. Rakyat hanya memiliki hak pakai dengan ijin dari Kasultanan. Jangka waktu penggunaan tanah tidak ditentukan, selama rakyat memenuhi aturan dan kewajiban yang telah ditentukan penguasa. Berbeda dengan rakyat, abdi dalem dan pembantunya memiliki hak atas tanah yang dikuasakan kepada mereka. Jadi, tanah kesultanan dapat digunakan untuk mendirikan rumah-rumah abdi dalem, keluarga sultan dan tanah yang dikelola masyarakat sebagai tanah magersari. Contoh lainnya pemanfaatan tanah kesultanan adalah sebagai tempat wisata, pendidikan, ibadah, makam dan kantor instansi Pemerintah Daerah Istimewa Yogyakarta, serat bangunanbangunan lain yang menunjang kemajuan setempat. Jika dilihat dari hal tersebut, maka pemanfaatan dan pengolaan tanah diperuntukkan untuk kepentingan kebudayaan, kepentingan sosial dan kepentingan publik demi kepentingan kesejahteraan rakyat (Sari et al., 2016).

Tanah magersari yang dikelola oleh masyarakat harus mendapatkan izin dari Kasultanan yang diurus oleh Panitiksmo. Surat Kekancingan Magersari sebagai tanda bukti perizinan yang didalamnya memuat a) tanah magersari tidak akan mendapatkan sertifikat atas hak tanah tersebut b) dilarang mendirikan bangunan kasultanan berhak menarik tanah megarsari bila diminta (Ardhini et al., 2018).

Berlakunya perdais Daerah Istimewa Yogyakarta No. 1 Tahun 2017 menujukkan adanya perubahan pada penyertipikatan tanah Sultanaat Ground dan Pakualaman Ground yang mengalami peningkatan secara tersetruktur, sistematis dan massif yang diharapkan dapat menciptakan kepastian hukum. Menurut Undang-Undang No. 1 Tahun 2017 baik tanah Kasultanan maupun Tanah Kadipaten Daerah Istimewa 
Yogyakarta berupa Tanah Keprabon dan Tanah bukan. Tanah Kasultanan dan Kadipaten selain digunakan untuk kepentingan kasultanan dan abdi dalem keraton juga dapat dimanfaatkan oleh masyarakat atau institusi untuk kepentingan sosial dan kesejahteraan masyarakat. Hal ini sesuai dengan tujuan pada Undang-Undang No. 32 Tahun 2004, dengan otonomi daerah untuk mensejahterakan masyarakat. Pengelolaan dan pemanfaatan tanah Kasultanan dan Kadipaten dapat digunakan oleh masyarakat atau institusi, meskipun hak kepemilikan sepenuhnya milik Kasultanan dan Kadipaten dengan ijin berupa surat kekancingan (Marsudi, 2014).

\section{KESIMPULAN}

Hubungan antara sistem pertanahan hukum nasional (UUPA) dan hukum adat (Rijkshblaad) di Daerah Istimewa Yogyakarta menyebabkan permasalahan dalam kepastian hukum. Akan tetapi dengan adanya Undang-Undang Nomor 13 Tahun 2012, Daerah Istimewa Yogyakarta memiliki kewenangan otonom untuk mengatur rumah tangganya sendiri termasuk sistem pertanahan yang berbeda dengan daerah lain. Otonomi khusus yang dimiliki oleh D.I Yogyakarta diterapkan untuk menjaga asal usul sejarah yang tidak dapat dipisahkan dari adat istiadat sebagai suatu kebiasaan yang tidak mudah dilepaskan. Otonomi daerah dibentuk menurut Undang-Undang No. 32 Tahun 2004 dengan tujuan untuk kepentingan kesejahteraan masyarakat. Pengelolaan dan pemanfaatan tanah Kasultanan dan Kadipaten digunakan untuk kepentingan masyarakat diantaranya dalam bidang kebudayaan, pendidikan, sosial dan publik. Untuk menggunakan tanah Kasultanan dan tanah Kadipaten perlu memahami bahwa kewenangan hak milik tanah sepenuhnya milik Kasultanan dan Kadipaten dengan perizinan berupa surat kekancingan yang diurus oleh panitikismo. Supaya meminimalisir terjadinya konflik sengketa tanah antara rakyat dan Kasultanan.

\section{BIBLIOGRAFI}

Alivia, D. (2019). Politik Hukum Pengaturan Pemerintahan Daerah yang Bersifat Khusus atau Bersifat Istimewa di Indonesia. Rechtidee, 14(2), 150-166.

Annafie, K., \& Nurmandi, A. (2017). Kelembagaan otonomi khusus (otsus) dalam mempertahankan nilai-nilai kebudayaan di provinsi daerah istimewa yogyakarta. Journal of Governance and Public Policy, 3(2), 304-338.

Ardhini, N., Yunianto, T., \& Isawati, I. (2018). Pengelolaan Tanah Magersari Keraton Yogyakarta Tahun 1984-2013 Dan Relevansinya Dalam Pengayaan Materi Mata Kuliah Sejarah Lokal. Candi, 18(2), 15.

Baharudin, B. (2016). Desain Daerah Khusus/Istimewa dalam Sistem Negara Kesatuan Republik Indonesia Menurut Konstitusi. Masalah-Masalah Hukum, 45(2), 85-92.

Jati, W. R. (n.d.). Politik Agraria Di Yogyakarta: Identitas Partrimonial \& Dualisme Hukum Agraria (Politic Of Agrarian In Yogyakarta; Patrimonial Identity 7 Agrarian Law Dualism). Jurnal Legislasi Indonesia, 11 .

Lestarini, R. (2018). Kebijakan Pertanahan Bagi Wni Keturunan Tionghoa Di Yogyakarta: Diskrimasi Atau Diskriminasi Positif. Jurnal Hukum \& Pembangunan, 
$48(1), 44-63$.

Nadir, S. (2013). Otonomi daerah dan desentralisasi Desa: Menuju pemberdayaan masyarakat desa. Jurnal Politik Profetik, 1(1).

Putriyanti, E. D. (2014). Dualisme Penerapan Hukum Pertanahan di Daerah Istimewa Yogyakarta. Ilmu Dan Budaya, 38(38), 4473-4487.

Sari, P. A., Silviana, A., \& Prasetyo, A. B. (2016). Pengakuan Hukum Tanah Nasional terhadap Tanah Keraton Yogyakarta setelah Berlakunya Peraturan Daerah Istimewa Nomor 1 Tahun 2013 tentang Kewenangan dalam Urusan Keistimewaan Daerah Istimewa Yogyakarta. Diponegoro Law Journal, 5(4), 1-16. 